\title{
Lean Job Design and Musculoskeletal Disorder Risk: A Two Plant Comparison
}

\author{
Sarah K. Womack, Thomas J. Armstrong, and Jeffrey K. Liker \\ Department of Industrial and Operations Engineering, University of Michigan, \\ Ann Arbor, MI 48109, USA
}

\begin{abstract}
This study examined the relationship between lean job design and work-related musculoskeletal disorder (WMSD) risk factors. Repetition, force, and posture were assessed for a sample of 56 production jobs across departments at a lean automobile-manufacturing plant and compared to 56 similar jobs at a traditional automobile-manufacturing plant. The results showed greater productivity in the lean plant: less waiting $(p=.006)$ and walking $(p<.001)$; and greater repetition exposure $(p=.001)$. The mean rating for repetition was 5.5 in the lean plant, compared to 5.0 in the traditional plant based on the Latko (1997) hand activity level scale. However, the lean plant had significantly lower peak hand force ratings $(p=.01)$. When examining force and repetition combined, the lean plant had a lower percentage of jobs above the American Conference for Governmental Industrial Hygienists (ACGIH)-recommended Threshold Limit Value (TLV ${ }^{\circledR}$ ). The findings suggest that lean manufacturing does not necessarily increase workers' risk for WMSD injuries. (c) 2009 Wiley Periodicals, Inc.
\end{abstract}

\section{INTRODUCTION}

This study examines the relationship between work organization and job characteristics under lean manufacturing and work-related musculoskeletal disorder (WMSD) risk factors. "Lean manufacturing" was the term coined in the 1980s to describe the manufacturing techniques pioneered by top performing Japanese automotive firms, specifically Toyota's Production System (TPS; Krafcik, 1988; Womack, Jones, \& Roos, 1990). Womack et al. (1990) predicted that lean manufacturing would revolutionize manufacturing in the United States and abroad because its principles of teamwork, communication, continuous improvement, and waste elimination (Ohno, 1988; Suzaki, 1987) would lead to better quality, productivity, and market responsiveness (Womack et al., 1990; Womack and Jones, 1996). A lean production system continuously seeks to minimize waste (or non-value added work), which in the context of automobile manufacture is commonly grouped into 7 categories (Shingo, 1989; Suzaki, 1987): overproduction-producing sooner or more than the next downstream customer requires; waiting-idle time; defects-time lost making or fixing defective parts; inventory-parts waiting in process or in finished goods storage; material handling - redundant movement of parts; processing waste — redundant or inefficient steps in the process; and motion waste-movement that is inefficient or adds no value

Correspondence to: Sarah K. Womack, OMDD-ER, 25 Atlantic Ave., Erlanger, KY 41018. E-mail: womacks@umich.edu 
(Suzaki, 1987). To reduce these wastes, TPS developed and adopted systems such as justin-time (JIT) delivery of parts, work teams, product mix leveling (heijunka), quality control (jidoka), total preventative maintenance, and standardized work-all of which are associated with automotive lean manufacturing (Liker, 2004; Ohno, 1988; Shingo, 1989; Suzaki, 1987; Womack et al., 1990).

New systems of work organization have changed the landscape of labor-intensive work environments - subsequently, their effect on health and safety has become a research agenda item (National Institute for Occupational and Safety and Health [NIOSH], 2002). Past research linking lean manufacturing practices (Womack et al., 1990) to WMSD injuries and work stress (Babson, 1993; Brenner, Fairris, \& Ruser, 2004; Jackson and Martin, 1996; Leclerc et al., 1998; Lewchuk \& Robertson 1996; Parker, 2003; Parker and Slaughter, 1988, 1995) has created interest in finding the mechanisms that lend themselves to poor health outcomes, especially because lean practices have become widely adopted in manufacturing (Gittleman, Horrigan, \& Joyce, 1998; Osterman, 1994).

WMSD injuries in manufacturing environments are a common problem according to NIOSH (Bernard, 1997) and the National Research Council and Institute of Medicine (2001), and some researchers claim that the production logic of lean manufacturing, in particular, increases injury prevalence as a result of intensified work demands and reduced job control (Landsbergis, 1999; Landsbergis et al., 1998). Other researchers suggest that the implementation and management process (rather than the system itself) are significant factors in determining the effect of lean practices on injury prevalence (Adler, Goldoftas, \& Levine, 1997). In other words, if it is implemented or managed poorly, then lean manufacturing could degrade worker health outcomes; vice versa, if it's implemented and managed correctly, it could improve outcomes (Adler, 1998; Adler et al., 1997).

Few studies have actually examined the link between WMSD injuries and lean job design by assessing physical risk factors. Womack (2007) investigated the relationship between WMSD exposure and lean job design at an automobile assembly plant that implemented lean production practices. The results showed there was considerable variation in leanness and risk factors between jobs in the facility, suggesting the value of measuring the effects of lean practices at the job level (vis-à-vis the company level). The results also showed that when considering the combination of WMSD risk factors-force, posture, and repetitionno difference appeared between the high and low lean jobs. A limitation of that study was that the work site was not considered a "truly" lean manufacturing plant based on employee involvement and continuous learning and improvement (Liker, 2004; Womack et al., 1990). Furthermore, few studies have examined WMSD outcomes at exemplar lean manufacturing plants that have consistently applied lean principles and practices.

The aim of this study was to further examine the relationship between lean job design and WMSD risk by investigating differences in job characteristics that lend themselves to productivity and ergonomic risk differences at an exemplar lean manufacturing plant. A sample of 56 production jobs was taken from the lean manufacturing plant and compared to similar jobs at a traditional manufacturing plant. The plants are owned by two different companies. The lean plant is owned and operated by a Japanese company with exemplar lean practices, and the traditional plant is owned an operated by an American automotive company that is early in the process of learning lean methods. The American company has more advanced lean plants, but the one selected is relatively immature in lean practices.

The conceptual framework presented in Figure 1 shows the hypothesized links between lean manufacturing, work characteristics, injuries, and plant performance metrics. The exogenous "production system characteristics" construct depicts lean production and 


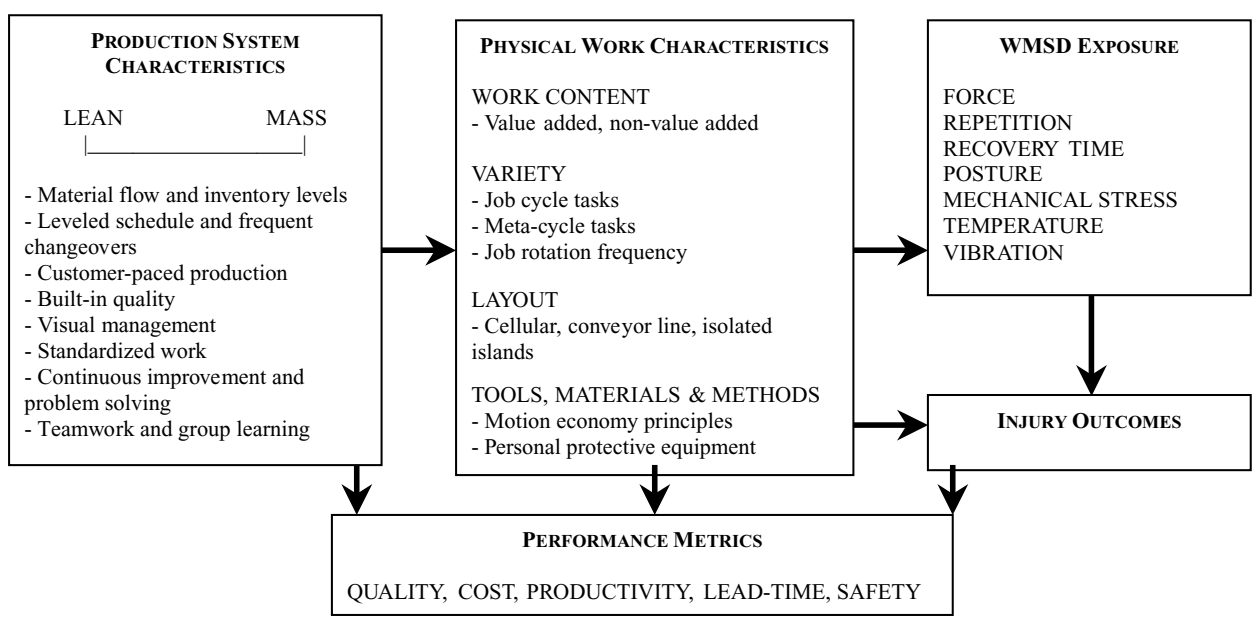

Figure 1 Conceptual framework for links between lean manufacturing implementation, work characteristics, and injury outcomes.

traditional (mass) production on a scale to suggest a continuum or "journey" toward becoming leaner (Liker, 1998) by simplifying material flow, reducing inventory, leveling the production schedule, increasing the frequency of changeovers, producing based on customer demand, and so forth. These practices ostensibly have an effect on how work is organized and performed, which then affects WMSD risk factors and injuries. The specific aims of this study are to determine 1) if jobs in the lean plant have an intensified work pace and greater ergonomic risk and 2) what organizational practices at the lean manufacturing site increase and/or attenuate ergonomic risk factors.

\subsection{Lean Practices at the Work Sites}

Although both automobile assembly plants were built in the 1980s, their production systems widely differ. The lean plant, which assembles mid-sized cars, began production according to lean manufacturing principles and TPS logic described by Womack et al. (1990) such as JIT delivery of parts, work teams and job rotation, leveled product mix (heijunka), quality systems (jidoka) including andon cords and error-proofing (poka yoke) devices, total preventative maintenance and daily housekeeping, standardized work, and continuous improvement (kaizen) activities (Liker, 2004; Ohno, 1988; Shingo, 1989; Suzaki, 1987; Womack et al., 1990).

The comparison plant assembled small trucks using traditional manufacturing methods. The traditional plant began adopting lean manufacturing practices in the late 1990s, but had only narrowly implemented TPS techniques and was thus considered a traditional plant, or as Lewchuk and Robertson (1996) would describe, a traditional plant changing to lean production. At the time of this study, this plant was scheduled to be replaced by a new facility based on more modern manufacturing practices.

Table 1 summarizes several observable differences at the job level between the lean and traditional production systems. The lean plant had leveled, mixed-model product lines. Three different vehicle models were assembled on the same line according to the sequence scheduled by production control. The team members' tasks could vary to some degree 
TABLE 1. Differences between the Lean and Traditional Plants

\begin{tabular}{|c|c|c|}
\hline Production Characteristic & Lean Plant & Traditional Plant \\
\hline Leveled product mix & 3 vehicles per assembly line & 1 vehicle per assembly line \\
\hline Team structure & $\begin{array}{l}5-8 \text { production workers per team } \\
\text { leader, } 3-4 \text { teams per group leader }\end{array}$ & $\begin{array}{l}\text { 18-20 production workers per } \\
\text { team leader }\end{array}$ \\
\hline Quality systems & $\begin{array}{l}\text { Andon cords pulled frequently and } \\
\text { responded to within seconds }\end{array}$ & $\begin{array}{l}\text { Andon cord pulls not prevalent } \\
\text { during observation period }\end{array}$ \\
\hline Job rotation/flexibility & Hourly rotation to each team job & $\approx 20 \%$ (voluntarily) rotate \\
\hline Standardized work & $\begin{array}{l}\text { Updated by team and used as } \\
\text { benchmark for continuous } \\
\text { improvement }\end{array}$ & $\begin{array}{l}\text { Updated by industrial } \\
\text { engineers }\end{array}$ \\
\hline
\end{tabular}

for each vehicle type, but most work elements were the same from cycle to cycle. The traditional plant assembled only one vehicle model, thus having mixed-model product lines was irrelevant. However, tasks could also vary to some degree depending on the option content, for example, 6-cylinder versus 8-cylinder engine. Similar to the lean plant, most work elements were the same from cycle to cycle.

Work teams existed at both plants. The lean team sizes ranged from five to eight production workers per team leader and three to four teams per group leader. In contrast, the traditional team sizes ranged from 18 to 20 production workers. Both plants had electronic andon systems (Suzaki, 1987) in which a worker on the line could pull a cord to signal the team leader or group leader for assistance or to stop the line for quality, part-fitting, timing, or other problems. Based on observations during visits to the lean plant, the andon cords were pulled frequently. The team leader responded in less than a minute to address the team member's problem. During visits to the traditional plant, andon cord pulls were not as prevalent. However, when they were pulled the team leaders also responded within a minute.

Job rotation occurred frequently in the lean plant. Team members rotated hourly or every 2 hours to every job on the team. In the traditional plant, job rotation was voluntary. According the plant personnel, approximately $20 \%$ of the workforce rotated about once per day.

Standardized work (with detailed instructions posted at the workstation) and "short" cycle times (production rate $\approx 60$ seconds) existed at both plants. However, standardized work was used differently between plants. Worker involvement in continuous improvement of standardized work was an integral part of the lean plant's production system. According to interviews with safety and production support personnel, production jobs changed frequently based on worker suggestions for standardized work improvements. Some suggestions improved ergonomics. For example, a swivel chair, suggested by a production worker, was engineered in-house and used to improve the ease of entering and exiting vehicles. Annually, the lean plant generates thousands of suggestions from production workers and implements more than $90 \%$. No data were obtained on the number of suggestions offered in the traditional plant.

According to safety and production support personnel at the lean plant, they were successful at continuous improvement because it is embedded in their work culture and the suggestions for improvement are responded to and implemented quickly by Kaizen teams, maintenance, or other specialists (depending on the suggestion). Many teams in the lean 
plant had process stack charts posted in their work area. Stack charts, similar to Gantt charts, had the work elements required for each job (on the team) on moveable cards "stacked" against takt time (cycle time, based on the customer demand rate). The team leader or team members used the stack charts to add, remove, or transfer work elements within the team based on changes in takt time (e.g., customer demand rate) or the process and/or continuous improvement suggestions.

\section{METHODS}

\subsection{Job Sample}

A sample of 56 production jobs from the traditional plant was randomly selected. Most of the jobs in the sample were selected using a random number generator and were matched with similar jobs from the lean plant, for example, seat installation and wheel attachment. Jobs with no direct comparison were not used, and some jobs were chosen with the intent of finding one directly comparable. The majority of jobs $(62.5 \%)$ were taken from Final Assembly, 17.9\% from Powertrain, 16.1\% from Body Weld, 3.6\% from Paint. Although most jobs were on a moving assembly line, $13 \%$ and $18 \%$ were off-line for the lean plant and traditional plant, respectively.

The type of work varied, including automated welding, manual assembly, and surface inspection. The assembly jobs varied across vehicle components, including: Trim (door, window and window wires, mag-beam panel); Chassis/Motor (coolant pipes, powertrain components, muffler, engine hoses/wires, fuel tank, serpentine belt, fan pulley, engine wire harness); and Final Assembly (fenders, seats, seatbelt, glove box, armrest, door trim, instrument panel, heater, carpet, rearview mirror, windshield, steering wheel, tires, tail light). The jobs in the sample were video recorded and analyzed off-site.

\subsection{Evaluating Leanness at the Job Level}

Leanness was evaluated at the job level using two lean factors: value added and non-value added work ratios (Womack, 2007). Value added work ratio was defined as the time the worker spends physically transforming the product over the total cycle time, for example, the fastener run down time. Non-value added work ratio was the time spent waiting and walking over the total cycle time. Other categories of non-value added work (Womack, 2007) were excluded because of their low occurrence in the data set. The higher the value added ratio, the leaner was the job; and the lower the non-value added ratio, the leaner was the job. To perform the lean assessment, each job in the sample was broken into individual work tasks, codified, and timed using traditional work measurement (Barnes, 1980).

\subsection{Measuring the Dependent Variables}

Each job in the sample was rated for low back and upper extremity WMSD exposure. Repetition was rated using the hand activity level (HAL) scale (ACGIH, 2005; Latko, 1997; Latko et al., 1997, 1999). HAL is based on the frequency of exertions (e.g., the number of exertions per cycle) and duty cycle (e.g., the percentage of cycle time the hand exerts a force $>5 \%$ ) of the busiest hand. HAL was evaluated by observation using a $10-\mathrm{cm}$ visual analog scale with verbal anchors. The scale ranged from 0 , which indicated that the hands were mostly idle, to 10 , which indicated that the hands were in rapid steady motion with difficulty keeping up. 
Posture was evaluated based on observations of non-neutral wrist, shoulder, and low back postures occurring during work tasks (Burt and Punnett, 1999; Juul-Kristensen, Hansson, Fallentin, Andersen, \& Ekdahl, 2001; Latko, 1997). Peak and (time weighted) average back posture ratings were based on the subjects' deviation from neutral (e.g., flexion/extension, side bending, twisting), normalized to a 10-point scale. For example, an average rating of 0 suggests that the subject's back was relatively neutral for the entire work cycle and an average rating of 10 suggests that the subject's back was in a maximum non-neutral position for the entire work cycle. Peak and (time-weighted) average shoulder posture ratings were based on the subjects' deviation from neutral (e.g., flexion/extension, abduction/adduction), normalized to a 10-point scale. Peak wrist posture ratings were based on the subjects' deviation from neutral (e.g., flexion/extension, radial/ulnar deviation), normalized to a 10-point scale. Average wrist posture was not evaluated because of the difficulty in observing the (small) joint using video recordings (Lowe, 2004a).

Peak hand force was also evaluated by observation. Force ratings were based on the percentage of the subjects' estimated maximum voluntary contraction (\%MVC) and normalized to a 10-point scale, where 0 indicated no force and 10 indicated maximum force produced by the busier hand. Benchmarks and visual cues such as fluidity of motion, use of body weight, facial expressions, unnatural postures, and bulging muscles (Latko, 1997; Marshall \& Armstrong, 2004) were used to estimate the subjects' hand force. Force, HAL, and posture were rated by three observers working in pairs (Ebersole \& Armstrong, 2002, 2004, 2005; Ebersole, Lau, \& Armstrong, 2005). Agreement between raters was a requirement; for example, if a score between two raters differed by more than 1 point, that risk factor was discussed and re-rated until consensus was reached.

\subsection{Statistical Analysis}

Descriptive statistics were used to summarize variation in job leanness and WMSD factors within each plant. To determine if there were statistical differences in ergonomic risk between plants, paired $t$ tests were used for the seven outcome variables at $\alpha$ levels of .05. Based on the literature that links lean manufacturing to faster work pace and higher injury incidences, the following hypotheses were tested:

$$
\begin{aligned}
& \mathrm{H}_{0}: \mathrm{L}_{i}=\mathrm{T}_{i} \\
& \mathrm{H}_{1}: \mathrm{L}_{i}>\mathrm{T}_{i}
\end{aligned}
$$

where $\mathrm{L}_{i}$ and $\mathrm{T}_{i}$ were the $i$ th WMSD factor (repetition, force, and posture) in the lean and traditional plant, respectively.

\section{RESULTS}

As expected, the lean plant was leaner (e.g., less non-value added work) than the traditional plant at the job level; $68 \%$ of the lean plant jobs had the same or greater value added work content compared to the traditional plant. Table 2 shows the percentage means (and standard deviations) of the value added and non-value added work content for both plants. Non-value added work, predominantly wait and walk time, was significantly lower in the lean plant; $52 \%$ of the lean plant jobs had less non-value added work. Workers spent less time, on average, waiting for a machine to complete its cycle and/or waiting for the next 
TABLE 2. Sample Means (and Standard Deviations) of Lean Factors for Each Plant

\begin{tabular}{lccc}
\hline Job (Cycle) Activity & Lean $(n=56)$ & Traditional $(n=56)$ & $p$ Value \\
\hline Non-value added: Wait time & $0.03(.08)$ & $0.08(.13)$ & 0.006 \\
Non-value added: Walk time & $0.14(.10)$ & $0.19(.11)$ & $<.001$ \\
Non-value added total & $0.17(.12)$ & $0.27(.18)$ & $<.001$ \\
Value added work content & $0.22(.11)$ & $0.22(.13)$ & 0.44 \\
\hline
\end{tabular}

TABLE 3. Sample Means (and Standard Deviations) of WMSD Factor Ratings for Each Plant

\begin{tabular}{lccc}
\hline Risk Factor & Lean $(n=56)$ & Traditional $(n=56)$ & $p$ Value \\
\hline HAL & $5.5(0.8)$ & $5.0(1.1)$ & 0.001 \\
Peak hand force & $4.5(2.1)$ & $5.2(2.0)$ & 0.01 \\
Back posture: Average & $0.5(0.6)$ & $0.6(0.8)$ & 0.10 \\
Back posture: Peak & $3.1(1.9)$ & $3.6(2.1)$ & 0.09 \\
Shoulder posture: Average & $1.4(0.8)$ & $1.4(0.9)$ & 0.44 \\
Shoulder posture: Peak & $7.4(1.4)$ & $7.5(1.6)$ & 0.41 \\
Wrist posture: Peak & $6.8(2.0)$ & $6.4(2.2)$ & 0.15 \\
\hline
\end{tabular}

vehicle to enter his/her work area after completing the required tasks. Workers also walked less in the lean plant because parts were presented closer to the point of use. It was often the case in the traditional plant that tools and materials were stored line side, which required walking to and from the parts rack several times per cycle. In contrast, the lean plant had kitted parts inside of the vehicle and small push carts with parts and tools to reduce the number of line-side return trips.

Table 3 shows the means (and standard deviations) of the ergonomic risk factors for both plants. As expected, repetition was higher (5.5 on the HAL scale) at the lean plant; $63 \%$ and $5 \%$ of the jobs had higher or the same HAL rating, respectively. Peak hand force was lower at the lean plant, which is contrary to the hypothesis; $48 \%$ and $13 \%$ of the lean jobs had lower and the same force rating, respectively, as the traditional jobs. The five posture ratings presented in Table 3 were not statistically different for the two plants (at the .05 significance level): $55 \%$ and $5 \%$ of the lean jobs had lower and the same average back posture rating, respectively; $60 \%$ and $2 \%$ of the lean jobs had lower and the same peak back posture rating, respectively; $48 \%$ and $4 \%$ of the lean jobs had lower and the same average shoulder posture rating, respectively; $48 \%$ and $5 \%$ of the lean jobs had lower and the same peak shoulder posture rating, respectively; and $36 \%$ and $4 \%$ of the lean jobs had lower and the same peak wrist posture rating, respectively.

To investigate how peak hand force and repetition (combined) affected hand-wrist WMSD exposure, both risk factors were plotted on the ACGIH TLV ${ }^{\circledR}$ (see Figures 2 and 3). The upper (bold) line on the $\operatorname{TLV}^{\circledR}$ represents the combinations of normalized peak hand force and HAL associated with a significant increase in prevalence of WMSDs, based on epidemiological research. Jobs at or above the $\operatorname{TLV}^{\circledR}$ should be redesigned to reduce risk 


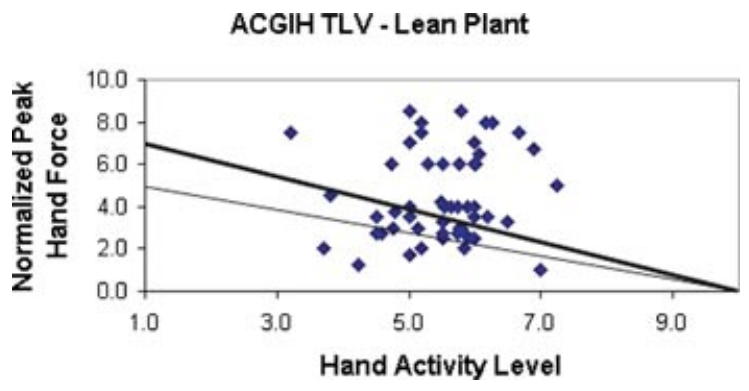

Figure 2 Lean plant's repetition and force ratings $(N=56)$ plotted on the ACGIH TLV ${ }^{\circledR}$ — $59 \%$ above TLV.

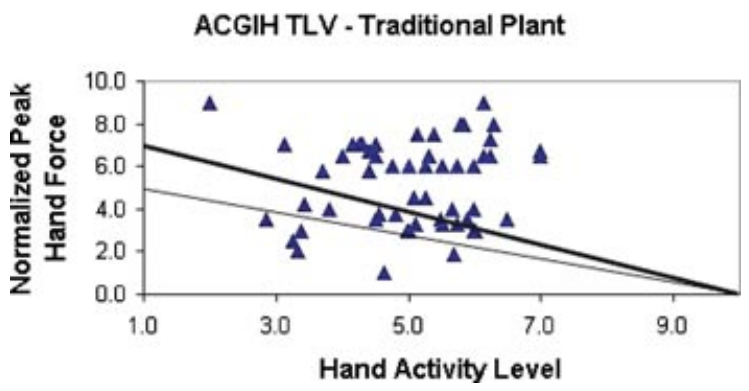

Figure 3 Traditional plant's repetition and force ratings $(N=56)$ plotted on the ACGIH TLV ${ }^{\circledR}$ $64 \%$ above TLV.

of injury, fatigue, and/or discomfort. The lower line is an Action Limit for which general controls are recommended (ACGIH, 2005). The number (and proportion) of jobs above the $\operatorname{TLV}^{\circledR}$ was lower, but not statistically significant, for the lean plant. Thirty-three (or 59\%) jobs at the lean plant were in the high exposure region compared to 35 (or 64\%) at the traditional plant.

\section{DISCUSSION}

\subsection{Work Pace}

The first aim of this study was to determine if production jobs in an exemplar lean manufacturing environment have an intensified work pace and greater ergonomic risk compared to a traditional manufacturing environment. The data in Table 3 showed that repetition was higher in the lean plant (5.5 compared to 5.0 on the HAL scale), which is consistent with the findings of Lewchuk and Robertson (1996), who studied 16 Canadian automotive components firms and found that subjects in the lean firm reported having an increased work pace. Past epidemiological research found that a 1-unit increase in HAL had an associated odds ratio of 1.17 for two outcomes: discomfort and symptoms consistent with carpal tunnel syndrome (Latko et al., 1999). Although the risk of WMSD injury was slightly higher in the lean plant, there was no evidence that workers had difficulty keeping up (e.g., 9-10 on the HAL scale) because the maximum HAL rating was 7.25 (compared to 7.0 for the traditional plant). 
The higher HAL ratings in the lean plant can be explained by differences in work characteristics. The average amount of waiting and walking in the lean job cycle was $3 \%$ and $14 \%$, respectively, compared to $8 \%$ and $19 \%$ in the traditional plant (see Table 2). Wait and walk time tends to reduce hand exertions and thus repetition exposure, which is consistent with the findings of Womack (2007), who found that non-value added work (walking, waiting, and poor presentation) was negatively associated with HAL.

It should be noted that there was no a priori hypothesis that the "short" cycle time (60 seconds) of many lean production plants (Adler et al., 1997; Fucini and Fucini, 1990; Graham, 1995; Parker and Slaughter, 1995) would increase repetition exposure. Although several past epidemiological studies have used cycle time to predict WMSD injuries (Armstrong, Fine, Goldstein, Lifshitz, \& Silverstein, 1987; Schierhout, Meyers, \& Bridger, 1995; Silverstein, Fine, \& Armstrong, 1986), recent research suggests that cycle time alone does not sufficiently measure hand repetition or subsequent stress on muscles and other soft tissue (Latko et al., 1997). The impact of designing jobs with a steady work pace (e.g., working 57 seconds of a 60-second cycle) will depend on other job characteristics, discussed later.

\subsection{Forceful Exertions}

The results showed that exposure to high hand forces was lower in the lean plant, 4.5 compared to 5.2 (see Table 3). This difference can be explained in part by the lean plant's principle of jidoka (Liker, 2004; Ohno, 1988; Shingo, 1989; Suzaki, 1987; Womack et al., 1990) and focus on process quality — which inputs include quality parts, tools, part presentation, and work methods. The lean plant aimed to build quality into processes to "get it right the first time." Quality is often thought of as product quality-lack of defects in the process. The lean plant took this a step further and developed processes that were easier to perform and less prone to error. This focus on quality positively impacted work characteristics and often translated into better ergonomics, such as better part fit. Table 4 lists several examples of how the principle of process quality led to lower force exposure (compared to the traditional plant).

Although the lean plant had higher repetition, hand/wrist exposure was attenuated by having lower forces. Notwithstanding the numerous jobs above the TLV ${ }^{\circledR}$ in Figure 2, lean manufacturing and TPS techniques do not appear to increase risk of injury compared to traditional methods (see Figure 3), as some conclude (Landsbergis, 1999). The difference in proportion of jobs above the TLV ${ }^{\circledR}$ between the two plants was not significant.

\subsection{Non-Neutral Postures}

It was hypothesized that non-neutral postures of the wrist, shoulder, and low back would be greater for the lean plant based on the claim that lean manufacturing jobs have more ergonomic risk. The data, however, showed no significant difference between the two plants (at .05 significance levels). On the contrary, non-neutral back posture was greater in the traditional plant (at .10 significance levels); see Table 3. These results are consistent with those of Lewchuk and Robertson (1996), who found no increase in worker reports of awkward postures for jobs in the lean plant. Furthermore, given the lean plant's higher level of leanness, and ostensibly productivity (reduced walking and waiting per cycle), it is plausible that lean jobs were designed for better working postures because the traditional jobs had much more recovery time to reduce their time-weighted posture ratings. 
TABLE 4. Examples Comparing Differences in Job Characteristics and Peak Hand Force Ratings

\begin{tabular}{|c|c|c|c|c|}
\hline $\begin{array}{l}\text { Process } \\
\text { Quality Inputs }\end{array}$ & Task & $\begin{array}{l}\text { Force } \\
\text { (Lean) }\end{array}$ & $\begin{array}{c}\text { Force } \\
\text { (Traditional) }\end{array}$ & Description of Difference \\
\hline Quality parts & $\begin{array}{l}\text { Attach glove } \\
\text { box }\end{array}$ & 3.25 & 9.0 & $\begin{array}{l}\text { Parts were forced fit by using hand } \\
\text { as hammer on traditional job. }\end{array}$ \\
\hline Quality tools & $\begin{array}{l}\text { Run down } \\
\text { fasteners }\end{array}$ & 4.5 & 5.8 & $\begin{array}{l}\text { Large (heavier) power tool was used } \\
\text { to run down fasteners. Medium } \\
\text { sized power tools with better grip } \\
\text { were used on lean job. }\end{array}$ \\
\hline \multirow[t]{2}{*}{$\begin{array}{l}\text { Quality part } \\
\text { presentation }\end{array}$} & $\begin{array}{l}\text { Attach right } \\
\text { hand door }\end{array}$ & 3.25 & 5.75 & $\begin{array}{l}\text { Aligning door required supporting } \\
\text { its weight with one hand. A } \\
\text { fixture was used to eliminate } \\
\text { holding door on lean job. }\end{array}$ \\
\hline & $\begin{array}{l}\text { Transport panel } \\
\text { with hoist }\end{array}$ & 2.75 & 6.5 & $\begin{array}{l}\text { Hoist was initiated/pulled with one } \\
\text { hand due to rack arrangement. } \\
\text { Hoist was initiated/pulled with } \\
\text { two hands due to parallel rack } \\
\text { arrangement on lean job. }\end{array}$ \\
\hline Quality methods & $\begin{array}{l}\text { Attach hose to } \\
\text { powertrain }\end{array}$ & 2.5 & 7.5 & $\begin{array}{l}\text { Attaching hose required rocking } \\
\text { back and forth. Hose attached } \\
\text { smoothly with lubricant on lean } \\
\text { job. }\end{array}$ \\
\hline
\end{tabular}

\section{PLAN-DO-CHECK-ACT ON HEALTH AND OTHER MODERATORS}

The second aim of this study was to determine what aspects of lean manufacturing increase or attenuate ergonomic risk factors. The results showed that continuously reducing nonvalue added content to increase productivity can increase repetition exposure, but focusing on process quality can attenuate hand force exposure. Although both the lean and traditional plants in this study invest in ergonomics, this section examines the organizational practices of the lean plant that result in high productivity and ergonomic job design. The focus is on the lean plant exclusively because of the specific interest in whether and how lean organizations achieve higher quality and lower costs without compromising safety. At this particular lean site, these practices helped reduce recordable injuries by $19 \%$ (on average) from 2000 to 2006.

The product development team uses the company's North American Ergonomics Guidelines and historical injury data to improve the design for manufacture of new vehicles early in the product development phase. They also get input from manufacturing in this early phase. During the preproduction stage, a highly skilled "Pilot team" composed of production workers and support personnel from all areas of the factory use three-dimensional simulation software to predict ergonomic risk and develop standard work procedures. The Pilot team then builds vehicles, identifies ergonomic problems along with other workability issues, and makes design recommendations and/or work method improvements to reduce risk. The Pilot team works with an Early Symptoms Investigation (ESI) team to evaluate ergonomic risk such as upper and lower limb postures, repetition, push/pull forces, and pinch points. Every job is evaluated and categorized into the high, moderate, or low risk 
group (using a checklist). The ESI, Pilot, and Kaizen teams work with engineers to develop countermeasures to reduce the ergonomic burden on high and moderate risk jobs.

At the start of production, the ESI team works with the various production groups, that then own the processes, to train the production workers on standardized work and ergonomics. They re-evaluate high and moderate risk jobs and other jobs based on worker feedback, and develop countermeasures for the problem jobs. Workers are also empowered by team leaders and group leaders to implement solutions to problems where feasible. When the line reaches its full production rate, the ESI team will perform a final cut of ergonomic evaluations of all jobs, and again, work with production support and engineers to develop countermeasures for the problem jobs. This cyclical monitoring, evaluation, and proactive development of countermeasures is part of the lean plant's Plan-Do-Check-Act (PDCA) approach to job improvement. The PDCA model, developed by Edward Deming for continuous improvement, is continued after product launch because jobs change frequently due to takt (cycle) time changes, line rebalancing, and/or improvements made by the team members. This cyclical process generates an average of 145 ESI reports per month during normal production runs at the plant. In addition to these proactive measures, the safety group uses computerized injury logs to investigate injury trends, evaluate countermeasures, and diffuse best practices to group and team leaders.

Finally, training and job rotation are administrative controls used to reduce ergonomic problems at the lean plant. Ergonomics training is required for all production workers, team leaders, and group leaders. Team leaders, the first line of production support for workers, are responsible for coaching, training, and checking that team members consistently perform best practices (e.g., standardized work) and adhere to safety standards. Team leaders also respond to problems (especially part-fitting problems) encountered on the line by team members and use the opportunity for group learning and problem solving (Liker, 2004). Group leaders are also responsible for performing daily checks that best practices are followed as well as asking workers, "How's your health today?" The effectiveness of this training and these social practices is perhaps a question for future research.

The effectiveness of job rotation in reducing WMSD injuries is also a future research question (Frazer, Norman, Wells, \& Neumann, 2003; Jorgensen, Davis, Kotowski, Aedla, \& Dunning, 2005). Job rotation was practiced, in part, to reduce ergonomic stress at NUMMIa lean manufacturing plant joint venture between Toyota and General Motors (Adler et al., 1997). At the lean plant in this study, team members rotated throughout each job on the team hourly or every 2 hours. The obvious benefit of job rotation is the increase in variety, but it also increases awareness of job problems throughout the team to promote group process improvements.

To summarize, the lean plant achieved greater productivity while moderating ergonomic problems by integrating ergonomics in the vehicle design process, continuously monitoring and reducing burden on high and moderate risk jobs, training, team and group leader support, job rotation, worker involvement in continuous improvement and problem-solving activities, and learning from injury trends. These practices are consistent with the NIOSH (1997) elements of an effective ergonomics program and have led to a 19\% (on average) decline in OSHA recordable injuries, annually since 2002.

A more philosophical view of how lean manufacturing improves ergonomics is the "fragility" of the production system, which creates incentives for management to control injuries and lost work days. Because lean manufacturing seeks to operate with a minimum number of resources, management and production workers have mutual interest in maintaining a safe work environment, high worker morale, and low injury prevalence. 
Lean proponents argue that worker commitment and involvement in problem solving is a key enabler of lean production (Liker, 2004; MacDuffie, 1995; Ohno, 1988; Suzaki, 1987; Womack et al., 1990) and, in the absence of appropriate training, support, and attention to health and safety, the system will revert back to traditional mass production.

It should be noted that it is perfectly possible to use lean tools with a different manufacturing philosophy that ends up being harmful to workers. There is nothing inherent in the tools of lean production that would lead to a high focus on process quality, worker safety, or employee involvement. Companies that disregard the broader lean philosophy and simply use lean tools to eliminate non-value added activities such as walking are apt to increase work content and HAL; without the offsetting focus on parts placement, process quality, small lot size, and team leader support, workers may be at greater risk of negative health outcomes. It is suspected that past studies that have found negative consequences of lean production have included in their sample traditional companies using some of the lean tools without the broader philosophy. The lean plant in this study may well be more the exception as the philosophy has been embedded over decades of consistent leadership and practice.

\section{FUTURE STUDIES}

The sample size used in this study makes it difficult to generalize the results for all lean and traditional manufacturing organizations. However, this study does lay groundwork for future research on how lean manufacturing affects job design and WMSD risk. One challenge in the quest for better understanding the impact that lean manufacturing has on worker health is identifying firms that have practices consistent with the ideal lean methodology (e.g., a philosophy that supports people and the use of continuous improvement tools). Different results may appear in the absence these features, which would be more consistent with the research linking lean production to poor health outcomes (Landsbergis, 1999). Also, this study did not support with quantitative data the presumption that better lean implementation actually translates into better business performance (e.g., profitability). Access to these data was not available for either plant as the focus of the study was on job design.

Furthermore, future studies should investigate worker perceptions of job demands (e.g., work pace and effort/exertion), which are important factors in work performance and work stress (Genaidy \& Karwowski, 2003). Also, the lean assessment and ergonomic ratings were based on observation and therefore subject to rater bias in general (Lowe, 2004a, 2004b) and a specific potential bias due to the ergonomic raters not blinded to which facility was lean versus traditional. Finally, the cross-sectional design of this study failed to assess the longitudinal effects of leanness on job design and WMSD risk factors, nor did it evaluate the effects of job rotation by examining cumulative exposure.

\section{CONCLUSION}

Previous research linking lean manufacturing practices to WMSDs has created a need for research methods that better examine physical risk factors. The primary aim of this study was to examine the relationship between lean job design and WMSD risk at a lean manufacturing plant and compare ergonomic exposure to a traditional plant. A sample of 56 production jobs from each plant was analyzed. The results of this study suggest that lean manufacturing does not necessarily increase workers' WMSD risk so long as key features of the system are implemented-specifically, a focus on process quality. At the lean plant, the pursuit of 
better processes began with product design engineers and continued up the chain to the Pilot team and finally the production workers, who owned the process-each group challenged to create better processes through evaluation and problem solving. The safety group was also in place to support the production groups by performing formal ergonomic evaluations and evaluating countermeasures.

\section{REFERENCES}

Adler, P. (1998). In Paul Landsbergis (Ed.), Lean production and worker health: A discussion. New Solutions, 8, 499-523.

Adler, P., Goldoftas, B., \& Levine, D. (1997). Ergonomic, employee involvement, and the Toyota production system: A case study of NUMMI's 1993 model introduction. Industrial and Labor Relations Review, 50, 416-437.

American Conference for Governmental Industrial Hygienists (ACGIH). (2005). Hand activity level, 2005 TLV for chemical substances and physical agents and biological exposure limits. Cincinnati, ACGIH.

Armstrong, T. J., Fine, L. J., Goldstein, S. A., Lifshitz, Y. R., \& Silverstein, B. A. (1987). Ergonomic considerations in hand and wrist tendonitis. Journal of Hand Surgery, 12A, 830-837.

Babson, S. (1993). Lean or mean: The MIT model and lean production at Mazda. Labor Studies Journal, 18, 3-24.

Barnes, R. (1980). Motion and time study: Design and measurement of work. New York: Wiley.

Bernard, B. (Ed.). (1997). Musculoskeletal disorders and workplace factors: A critical review of the epidemiological evidence for work-related musculoskeletal disorders of the neck, upper extremity, and low back. Cincinnati, OH: U.S. Dept of Health, Education, and Welfare, Public Health Service, Centers for Disease Control and Prevention, National Institute for Occupational Safety and Health.

Brenner, M., Fairris, D., \& Ruser, J. (2004). Flexible work practices and occupational safety and health: Exploring the relationship between cumulative trauma disorders and workplace transformation. Industrial Relations, 43, 242-264.

Burt, S., \& Punnett, L. (1999). Evaluation of interrater reliability for posture observations in a field study. Applied Ergonomics, 30, 121-135.

Ebersole, M., \& Armstrong, T. J. (2002). Inter-rater reliability for hand activity level (HAL) and force metrics. Human Factor and Ergonomics Society Proceedings, Baltimore, MD.

Ebersole, M., \& Armstrong, T. J. (2004). An analysis of task-based self-assessments of force. Human Factors and Ergonomics Society Proceedings, New Orleans, Louisiana.

Ebersole, M., \& Armstrong, T. J. (2005). Analysis of an observational ratings scale for repetition, posture and force in selected manufacturing settings. Human Factors and Ergonomics Proceedings, Orlando, FL.

Ebersole, M., Lau, M., \& Armstrong, T. J. (2005). Task-based measurement of force in automobile assembly using worker self-assessment, observational analysis and electromyography. Human Factors and Ergonomics Society Proceedings, Orlando, FL.

Frazer, M., Norman, R., Wells, R., \& Neumann, W. (2003). The effects of job rotation on the risk of reporting low back pain. Ergonomics, 44, 904-919.

Fucini, J., \& Fucini, S. (1990). Working for the Japanese. New York: Free Press.

Genaidy, A. M., \& Karwowski, W. (2003). Human performance in lean production environment: Critical assessment of research framework. Human Factors and Ergonomics in Manufacturing, 13, $317-330$.

Gittleman, M., Horrigan, M., \& Joyce, M. (1998). "Flexible" workplace practices: Evidence from a nationally representative survey. Industrial and Labor Relations Review, 52, 99-115.

Graham, L. (1995). On the line at Subaru-Isuzu: The Japanese model and the American worker. Ithaca, NY: ILR/Cornell University Press.

Jackson, P., \& Martin, R. (1996). Impact of just-in-time on job content, employee attitudes, and well-being: A longitudinal study. Ergonomics, 39, 1-16.

Jorgensen, M., Davis, K., Kotowski, S., Aedla, P., \& Dunning, K. (2005). Characteristics of job rotation in the Midwest US manufacturing sector. Ergonomics, 48, 1721-1733. 
Juul-Kristensen, B., Hansson, G.-^̊., Fallentin, N., Andersen, J. H., \& Ekdahl, C. (2001). Assessment of work postures and movements using a video-based observation method and direct technical measurements. Applied Ergonomics, 32, 517-524.

Krafcik, J. F. (1988). Triumph of the lean production system. Sloan Management Review, 30(1), $41-52$.

Landsbergis, P. (1999). The impact of lean production and related new system of work organization on worker health. Journal of Occupational Health Psychology, 4, 108-130.

Landsbergis, P., Adler, P., Babson, S., Johnson, J., Kaminski, M., Lessin, N., et al. (1998). Lean production and worker health: A discussion. New Solutions, 8, 499-523.

Latko, W. (1997). Development and evaluation of an observational method for quantifying exposure to hand activity and other physical stressors in manual work. University of Michigan, Ann Arbor.

Latko, W., Armstrong, T., Foulke, J., Herrin, G., Rabourn, R., \& Ulin, S. (1997). Development and evaluation of an observational method for assessing repetition in hand tasks. American Industrial Hygiene Association Journal, 58, 278-285.

Latko, W., Armstrong, T., Franzblau, A., Ulin, S., Werner, B., \& Albers, J. (1999). Cross-sectional study of the relationship between repetitive work and the prevalence of upper limb musculoskeletal disorders. American Journal of Industrial Medicine, 36, 248-259.

Leclerc, A., Franchi, P., Cristofari, M., Delemotte, B., Mereau, P., Teyssier-Cotte, C., et al. (1998). Carpal tunnel syndrome and work organization in repetitive work: A cross sectional study in France. Occupational \& Environmental Medicine, 55, 180-187.

Lewchuk, W., \& Robertson, D. (1996). Working conditions under lean production: A worker-based benchmarking study. Asia Pacific Business Review, 2, 60-81.

Liker, J. (Ed.). (1998). Becoming lean: Inside stories of U.S. manufacturers. Portland, OR: Productivity Press.

Liker, J. (2004). The Toyota way. New York: McGraw Hill.

Lowe, B. (2004a). Accuracy and validity of observational estimates of wrist and forearm posture. Ergonomics, 47, 527-554.

Lowe, B. (2004b). Accuracy and validity of observational estimates of shoulder and elbow posture. Applied Ergonomics, 35, 159-171.

MacDuffie, J. P. (1995). Workers' roles in lean production: The implications for worker representation. In Steve Babson (Ed.), Lean work: Employment and exploitation in the global auto industry (pp. 41-53). Detroit: Wayne State University Press.

Marshall, M., \& Armstrong, T. (2004). Observational assessment of forceful exertion and the perceived force demands of daily activities. Journal of Occupational Rehabilitation, 14, 281-294.

National Institute for Occupational and Safety and Health (NIOSH). (1997). Elements of ergonomics programs: A primer based on workplace evaluations of musculoskeletal disorders. Department of Health and Human Services (NIOSH) Publication No. 97-117, Cincinnati, OH.

National Institute for Occupational and Safety and Health (NIOSH). (2002). The changing organization of work and the safety and health of working people: Knowledge gaps and research directions. Department of Health and Human Services (NIOSH) Publication No. 2002-116, Cincinnati, OH.

National Research Council and Institute of Medicine. (2001). Musculoskeletal disorders and the workplace: Low back and upper extremities. Panel on Musculoskeletal Disorders and the Workplace Commission on Behavioral and Social Sciences and Education National Research Council and Institute of Medicine, Washington, DC: National Academies Press.

Ohno, T. (1988). Toyota production system: Beyond large scale production. New York, NY: Productivity Press.

Osterman, P. (1994). How common is workplace transformation and who adopts it? Industrial and Labor Relations Review, 47, 173-188.

Parker, M., \& Slaughter, J. (1988). Management by stress. Technology Review, 91, 36-44.

Parker, M., \& Slaughter, J. (1995). Unions and management by stress. In Steve Babson (Ed.), Lean work: Employment and exploitation in the global auto industry (pp. 41-53). Detroit: Wayne State University Press.

Parker, S. (2003). Longitudinal effects of lean production on employee outcomes and the mediating role of work characteristics. Journal of Applied Psychology, 88, 620-634. 
Schierhout, G. H., Meyers, J. E., \& Bridger, R. S. (1995). Work related musculoskeletal disorders and ergonomic stressors in the South African workforce. Occupational \& Environmental Medicine, $52,46-50$.

Shingo, S. (1989). A study of the Toyota production system from an industrial engineering viewpoint. Cambridge, MA: Productivity Press.

Silverstein, B. A., Fine, L. J., \& Armstrong, T. J. (1986). Hand wrist cumulative trauma disorders in industry. British Journal of Industrial Medicine, 43, 779-784.

Suzaki, K. (1987). The new manufacturing challenge: Techniques for continuous improvement. New York: Free Press.

Womack, J., Jones, D., \& Roos, D. (1990). The machine that changed the world. New York: Rawson Associates.

Womack, S. (2007). A multi-methodological study of the effects of lean manufacturing practices on work-related musculoskeletal disorder risk factors and other injuries. Unpublished doctoral dissertation, University of Michigan, Ann Arbor.

Womack, J., \& Jones, D. (1996). Lean thinking: Banish waste and create wealth in your corporation. New York, NY: Simon and Schuster. 